\title{
Measles Virus-Substance P Receptor Interactions Possible Novel Mechanism of Viral Fusion
}

Greg Harrowe, Masato Mitsuhashi, and Donald G. Payan

Howard Hughes Medical Institute and Department of Medicine, University of California Medical Center, San Francisco, California 94143

\begin{abstract}
Measles virus (MV) encodes the fusion protein (F) that mediates cell fusion and intercellular spread of the virus, and is homologous to the carboxy terminus of the neuropeptide substance P (SP). In addition, the oligopeptide Z-D-Phe-L-PheGly, also homologous to $F$ and SP, inhibits MV fusion with target cells.' These observations raise the question of whether MV uses the SP receptor (SPR) during a specific phase of its infectious cycle. In this report, we examine the structural and functional consequences of this interaction and show, using cross-linking studies, that MV and SP specifically bind to a 52-58-kD protein, previously reported to comprise the SPR on human IM-9 lymphoblasts. Moreover, bound MV and SP are shown to reciprocally displace each other from these cells. In addition, we demonstrate that anti-SP antisera inhibits the cell-to-cell spread of MV, and that SP blocks MV fusion with target cells. These results indicate the presence of MV-SPR interactions during viral fusion, and suggest possible novel mechanisms for viral entry into cells. (J. Clin. Invest. 1990. 85:1324-1327.) measles virus • substance $P$ • fusion protein • viral infection
\end{abstract}

\section{Introduction}

The molecular mechanisms by which viruses bind to and infect specific tissues/cells to cause disease have yet to be fully characterized. Based on a number of recent studies, viruses may have evolved to use specific cell surface receptors that are important for endogenous cell-cell recognition mechanisms or for nonviral ligands. For example, it has been reported that rabies (1), vaccinia (2), Epstein-Barr (3), HIV-1 (4), and reovirus type $3(5)$ bind to the acetylcholine receptor, epidermal growth factor receptor, complement receptor, $T$ cell antigen, and adrenergic receptor, respectively. However, it is still unclear how viruses use these receptors during the various stages

Address reprint requests to Dr. D. G. Payan, Howard Hughes Medical Institute, Box 0724, U-426, University of California San Francisco, San Francisco, CA 94143.

Received for publication 25 August 1989 and in revised form 18 December 1989.

J. Clin. Invest.

(c) The American Society for Clinical Investigation, Inc. 0021-9738/90/04/1324/04 \$2.00

Volume 85, April 1990, 1324-1327 of viral attachment, fusion, replication, and spread into noninfected cells.

The envelope of measles virus (MV) ${ }^{1}$ contains two glycoproteins. The large hemagglutinin (HA) with a molecular weight of $\sim 80 \mathrm{kD}$, is responsible for initial virus attachment and hemagglutination of red blood cells (6), whereas the smaller fusion protein $(F)$ is involved in cell fusion and intercellular spread of the virus (7). The fusion activity of $F$ is generated by cleavage into a nonglycosylated $F 1$ peptide $(F 1)$ with a molecular weight of $41 \mathrm{kD}$, and a glycosylated $F 2$ peptide with a molecular weight of 18-20 kD. The amino terminus of $\mathrm{F} 1$ of $\mathrm{MV}$ is essential for its functional activity, as demonstrated by the fact that synthetic oligopeptides of similar structure to the $\mathrm{NH}_{2}$-terminus of $\mathrm{F} 1$ inhibit $\mathrm{MV}$ replication and cell-to-cell fusion (8). Interestingly, the $\mathrm{NH}_{2}$-terminus of F1, -Phe-Ala-Gly- is homologous to that of the carboxy terminus of the neuropeptide substance P (SP), -Phe-Phe-Gly-. Moreover, the oligopeptide Z-D-Phe-L-Phe-Gly has been shown to inhibit MV fusion (9), and SP has been reported to reduce the amount of $M V$ production (10). These data suggest that MV might use the SP receptor (SPR) during viral infection.

Here, we report the structural and functional consequences of the interaction between MV and SPR, and suggest possible novel mechanisms for MV entry into cells.

\section{Methods}

$R I A$. Guinea pig anti-MV polyclonal antibody (GP $\alpha \mathrm{MV}$ ) (NIH Research reference reagent) or normal guinea pig serum (Cappel Laboratories, Cochranville, PA) were diluted 1:10,000-1:30,000 with PBS and incubated in 96-well plates at $4^{\circ} \mathrm{C}$ overnight. Wells were then blocked with PBS containing $1 \%$ BSA-PBS at $4^{\circ} \mathrm{C}$ for $1 \mathrm{~h} .1 .0 \mathrm{OD}_{260} \mathrm{U}$ of MV were then added into each well and incubated at $4^{\circ} \mathrm{C}$ for $1 \mathrm{~h}$. After the excess MV was removed, various concentrations of normal rabbit serum (NRS) (Cappel Laboratories) or rabbit anti-SP polyclonal antibodies (Rab $\alpha S P$ ) were incubated at $4^{\circ} \mathrm{C}$ for $1 \mathrm{~h}$, and then $10,000 \mathrm{cpm}$ of ${ }^{125} \mathrm{I}$-protein $\mathrm{A}$ was incubated at $4^{\circ} \mathrm{C}$ for an additional 1 h. After washing with BSA-PBS containing $0.5 \%$ Tween-20, the $\gamma$-radioactivity of individual wells was determined in a $\gamma$-counter.

Immunoprecipitation of SP or MV-cross-linked proteins on IM-9 cells. Human IM-9 lymphoblasts (American Type Culture Collection, Rockville, MD) were suspended in fresh methionine-free RPMI and

1. Abbreviations used in this paper: DSP, dithiobis-(succinimidyl propionate); F, fusion protein; $F 1, F 1$ peptide; GP $\alpha M V$, guinea pig antiMV; MV, measles virus; NRS, normal rabbit serum; Rab $\alpha$ SP, rabbit anti-SP; SP, substance P; SPR, SP receptor; VSV, vesicular stomatitis virus. 
incubated with $0.1 \mathrm{mCi} / \mathrm{ml}\left[{ }^{35} \mathrm{~S}\right]$ methionine at $37^{\circ} \mathrm{C}$ for $4 \mathrm{~h}$ as previously described (11). The IM-9 cells were then cross-linked with $10^{-7}$ $\mathrm{M} \mathrm{SP}$ or $1.0 \mathrm{OD}_{260} \mathrm{U}$ of $\mathrm{MV}$ in the presence of $1 \mathrm{mM}$ dithiobis-(succinimidyl propionate) (DSP) (Pierce Chemical Co., Rockford, IL) at $4^{\circ} \mathrm{C}$ for $40 \mathrm{~min}$ as previously described (12). Cells were then lysed in lysis buffer $(0.2 \mathrm{M} \mathrm{NaCl}, 2.5 \mathrm{mM} \mathrm{MgCl}, 1 \%$ Triton X-100, $1 \mathrm{mM}$ PMSF, $0.1 \mathrm{mM}$ leupeptin, and $10 \mathrm{mM}$ Hepes, $\mathrm{pH}$ 7.2) and nuclear pellets were removed by centrifugation. Supernatants were incubated with GP $\alpha$ MV or Rab $\alpha S P$ at $4^{\circ} \mathrm{C}$ for $16 \mathrm{~h}$. Staph A cells were then added and centrifuged at $3,500 \mathrm{~g}$ for $20 \mathrm{~min}$ at $4^{\circ} \mathrm{C}$. Pellets were washed with $1 \%$ NP-40, $1 \%$ sodium deoxycholate, $0.1 \%$ SDS, $0.1 \mathrm{M}$ $\mathrm{NaCl}, 5 \mathrm{mM}$ EDTA, 0.02\% $\mathrm{Na}$ azide, $1 \mathrm{mM}$ PMSF, and $50 \mathrm{mM}$ Tris- $\mathrm{HCl}, \mathrm{pH} 7.4$, and immune complexes containing the proteins cross-linked to SP or MV were separated on SDS-PAGE under denaturing conditions (13), and autoradiography was conducted as previously described $(11,12)$.

Flow cytometric analysis of MV binding to IM-9 cells. $1 \mathrm{mg} / \mathrm{ml}$ of 5-(4,6-dichlorotriazinyl) aminofluorescein (Molecular Probes, Eugene, $\mathrm{OR}$ ) was incubated with $0.67 \mathrm{OD}_{260} \mathrm{U}$ of $\mathrm{MV}$ at room temperature for $1 \mathrm{~h}$ according to the method of McGrath et al. (14). Labeled MV was then applied to a column of Sepharose CL-4B which was equilibrated and run with $20 \mathrm{mM}$ Tris, $\mathrm{pH} 7.5,1 \mathrm{mM}$ EDTA and $0.1 \mathrm{M} \mathrm{NaCl}$ (14). The first peak on $\mathrm{OD}_{260}$ representing fluoresceinated $\mathrm{MV}$ was used for the binding assay. The resulting FITC-MV was active in the plaque formation assay. FITC-MV was then incubated with IM-9 cells at $4^{\circ} \mathrm{C}$ for $1 \mathrm{~h}$, and fluorescence of individual cells was analyzed in a fluorescent activated cell sorter (FACS IV; Becton Dickinson \& Co., Sunnyvale, CA) at $488 \mathrm{~nm}$ excitation and $522 \mathrm{~nm}$ emission.

$1.0 \mathrm{OD}_{260} \mathrm{U}$ of MV was also incubated with IM-9 cells for $1 \mathrm{~h}$ at $4^{\circ} \mathrm{C}$, and then incubated with GP $\alpha \mathrm{MV}(1: 300)$ at $4^{\circ} \mathrm{C}$ for $30 \mathrm{~min}$, followed by FITC-labeled goat anti-guinea pig antibody (G $\alpha \mathrm{GP})$ (Cappel Laboratories) $(1: 30)$ at $4^{\circ} \mathrm{C}$ for $30 \mathrm{~min}$. The fluorescence of individual cells was analyzed in a FACS as described above.

MV plaque formation. 100-200 plaque-forming units (PFU) of MV were added into confluent monolayer cultures of monkey kidney Vero cells and incubated for $1 \mathrm{~h}$ at $37^{\circ} \mathrm{C}$ for virus adsorption in the presence and absence of antibodies. After the viral innoculum was removed, minimum essential medium containing $100 \mathrm{U} / \mathrm{ml}$ penicillin, 100 $\mu \mathrm{g} / \mathrm{ml}$ streptomycin, $20 \%$ fetal calf serum, and $1 \%$ agarose was added to cell monolayers in the presence and absence of the respective antibodies, and incubated for $3 \mathrm{~d}$. Plaques were stained with neutral red and the number of plaques were counted on the 4th and 6th $\mathrm{d}$.

$V$ iral fusion. The fusion assay employed the fluorescent amphiphile octadecyl rhodamine B chloride $\left(R_{18}\right)$, which has been used to probe the fusion of viral and cell membranes (15). Purified MV and vesicular stomatitis virus (VSV) (kindly provided by Dr. J. E. White, University of California, San Francisco) were loaded with 15-20 nmol $R_{18}$ at $37^{\circ} \mathrm{C}$ for $1 \mathrm{~h}$, and unincorporated dye was separated from loaded viruses by spinning through a Sephadex G-50 column. Approximately

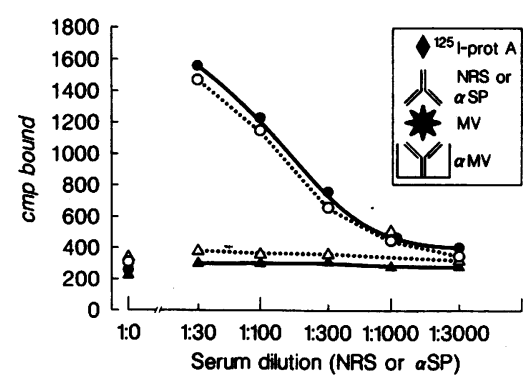

Figure 1. The recognition of MV by $\alpha S P$ antibodies. $1.0 \mathrm{OD}_{260} \mathrm{U}$ of MV were added into GP $\alpha$ MV-coated plates $(1: 10,000[0, \Delta]$ or $1: 30,000[\bullet, \Delta]$ dilution), and incubated at $4^{\circ} \mathrm{C}$ overnight. After excess MV was removed from the coated plates, various concentrations of $\operatorname{NRS}(\Delta, \Delta)$ or $\operatorname{Rab} \alpha \operatorname{SP}(0, \bullet)$ were incubated at $4^{\circ} \mathrm{C}$ for $1 \mathrm{~h}$. After the unbound antibody was removed, $10,000 \mathrm{cpm}$ of ${ }^{125} \mathrm{I}$-protein $\mathrm{A}$ were incubated at $4^{\circ} \mathrm{C}$ for an additional $1 \mathrm{~h}$, and then the $\gamma$-radioactivity of individual wells was determined. The inset summarizes the basic principle of this assay. Each value represents the mean of three wells from two separate experiments.

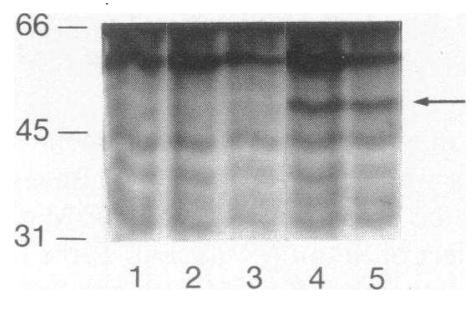

Figure 2. Immunoprecipitation of SP- and MVcross-linked proteins on IM-9 cells. ${ }^{35}$ S-biosynthetically labeled IM-9 cells were cross-linked with $10^{-7}$ M SP (lanes 2 and 4) or 1.0 $\mathrm{OD}_{260} \mathrm{U}$ of $\mathrm{MV}$ (lanes 3 and 5 ) in the presence of 1 $\mathrm{mM}$ DSP at $4^{\circ} \mathrm{C}$ for $40 \mathrm{~min}$. Cells were then lysed, and incubated with NRS (lanes 2 and 3), or RabaSP (lanes 4 and 5) at $4^{\circ} \mathrm{C}$ for 16 h. Lane 1 represents labeled cells cross-linked with DSP alone, solubilized as for lanes 2-5, and immunoprecipitated with RabaSP.

Staph A cells were added, and the immune complexes containing the proteins cross-linked to SP or MV were separated by SDS-PAGE under denaturing conditions, and autoradiography was conducted as described in the text.

5-10 $\mu \mathrm{g}$ of loaded viruses were adsorbed to Vero cells for $1 \mathrm{~h}$ at $4^{\circ} \mathrm{C}$. The cells were then resuspended in $0.5 \mathrm{ml}$ of PBS, and transferred to the fluorimeter cuvette, prewarmed at $37^{\circ} \mathrm{C}$. The change in fluorescence was measured in a fluorimeter (model 650-40; Perkin Elmer, Norwalk, CT) at $560 \mathrm{~nm}$ excitation and $585 \mathrm{~nm}$ emission.

\section{Results and Discussion}

Initial experiments were carried out to investigate the structural similarities between MV and SP: We examined if RaboSP antibodies recognize epitopes on MV using a modified sandwich RIA. As shown in Fig. 1, RabosP recognizes MV at concentrations as low as 1:600, whereas NRS failed to bind to MV even at a 1:30. The possibility that MV and SP bind to the same proteins was examined by immunoprecipitating peptide and virus cross-linked to IM-9 cells with the above antibodies. Human IM-9 cells, known to express the SPR (12), were biosynthetically labeled with $\left[{ }^{35}\right.$ S]met as previously described (11), and cell surface proteins were specifcally cross-linked to either SP or MV using a thiol cleavable cross-linking agent DSP. As shown in Fig. 2, RabaSP (lanes 4 and 5) specifically precipitated a protein with the apparent molecular weight of 52-58 kD in both MV- (lane 5) and SPcross-linked (lane 4 ) cells compared with control serum (lanes 2 and 3). Our previous studies using specific [ ${ }^{125}$ I]SP crosslinking (12) and receptor affinity chromatography (16), indicated that the molecular weight of the SPR on IM-9 cells was $52-58 \mathrm{kD}$. Thus the.52-58-kD protein recognized by both MV and SP in these immunoprecipitation assays might be part of the SPR on IM-9 cells. It should be noted that antiidiotypic antibodies to MV occasionally immunoprecipitated a protein on the surface of Vero cells in the range of 52-58 $\mathrm{kD}$ (17), which may represent the same protein that SP and MV recognize on IM-9 cells.

To analyze further the possibility that MV might be recognizing the SPR on IM- 9 cells, we have examined the effects of MV and the oligopeptide, Z-D-Phe-L-Phe-Gly, on [ $\left.{ }^{125} I\right] S P$ binding to these cells (12). MV and Z-D-Phe-L-Phe-Gly inhibited [ ${ }^{125}$ I]SP binding to its receptor on IM-9 cells in a dose-dependent manner with an $\mathrm{EC}_{50}$ of $\sim 1.0 \mathrm{OD}_{260} \mathrm{U}$ and $3 \times 10^{-6}$ $M$, respectively (data not shown). Furthermore, we have also tested MV binding on IM- 9 cells in a FACS. FITC-labeled MV bound to IM-9 cells in a dose-dependent manner (data not shown), and at equilibrium binding, FITC-MV was reversibly displaced with unlabeled MV (Fig. $3 A$ ). The binding of MV to 
IM-9 cells, detected by a GP $\alpha$ MV and a secondary FITC-labeled $\mathrm{G} \alpha \mathrm{GP}$, was also reversibly displaced with unlabeled SP (Fig. 3 B).

The hypothesis that MV may use the SPR during the attachment and fusion process was explored further in functional studies by examining the activity of RabaSP on MV plaque formation, and the effect of SP on MV fusion. Table I shows the effect of GP $\alpha \mathrm{MV}$ and Rab $\alpha \mathrm{SP}$ on MV plaque formation. The persistence of MV inhibition at day 6 compared with day 4 implies neutralization of MV by GP $\alpha \mathrm{MV}$. In contrast, the lack of inhibition at day 6 compared with day 4 in the Rab $\alpha$ SP-treated plates suggests that the delay in the MV cytopathic effect caused by Rab $\alpha$ SP is due principally to its inhibition of viral induced cell-to-cell fusion (18). It has been shown that MV-infected cells express viral $\mathrm{HA}$ and $\mathrm{F}$ on the cell surface, which are replaced every 9-10 h (19), and because antibodies are capable of capping with these cell surface viral antigens (20), the concentration of antibodies in this assay may decrease during incubation if cells are infected with MV. Therefore, our data suggest that GP $\alpha$ MV inhibits MV infection, whereas Rab $\alpha$ SP fails to completely inhibit MV infection, but nevertheless significantly inhibits the spread of the MV most likely by inhibiting viral induced cell-cell fusion processes (18).

The effect of SP on viral fusion was analyzed further using the fluorescent dye $R_{18}$ (15). This assay is based on the evidence that release of fluorescent self-quenching of dye from viral-membrane to cell-membrane reflects the virus-cell fusion process. Fig. 4 shows the fusion kinetics of $R_{18}$-loaded $M V$ with Vero cells which were pretreated with or without Z-DPhe-L-Phe-Gly or SP. The loaded $R_{18}$ within MV diffused into Vero cell membranes rapidly after warming up at $37^{\circ} \mathrm{C}$, and fluorescence intensity was increased, demonstrating MV fusion with Vero cells (Fig. $4 A$ ). In contrast, the slope of $R_{18}$ fluorescence in SP (Fig. $4 \mathrm{~B}$ ) and the oligopeptide- (Fig. $4 \mathrm{C}$ ) pretreated cells was significantly decreased compared with that of control cells. Three experiments indicated that the percentage of control (slope of treated cells/slope of control cells)

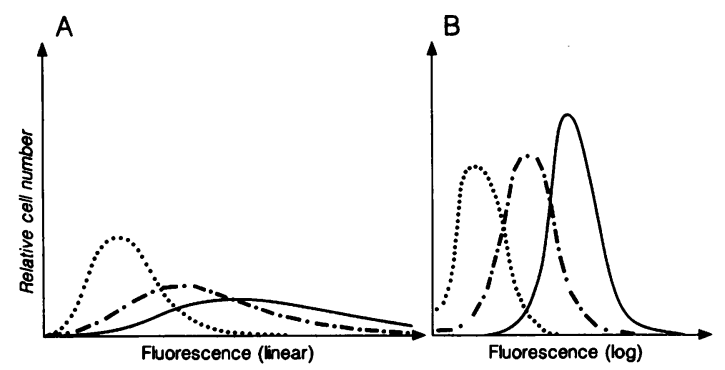

Figure 3. FACS analysis of MV binding to IM-9 cells. $(A)$ Binding of FITC-labeled MV on IM-9 cells. FITC-MV was incubated with IM-9 cells at $4^{\circ} \mathrm{C}$ for $1 \mathrm{~h}$, and fluorescence of individual cells was analyzed in a FACS as described in the text. $(\cdot \cdots),(-\cdot \cdot-)$, and $(-)$ indicate the histogram of unstained IM-9 cells, and FITC-MV-stained IM-9 cells in the presence and absence of unlabeled MV, respectively. (B) Displacement of MV binding to IM-9 cells by SP. IM-9 cells were mixed with $\mathrm{MV}$ for $1 \mathrm{~h}$ at $4^{\circ} \mathrm{C}$, then incubated with $\mathrm{GP} \alpha \mathrm{MV}$ at $4^{\circ} \mathrm{C}$ for $30 \mathrm{~min}$, followed by FITC-labeled $\mathrm{G} \alpha \mathrm{GP}$ at $4^{\circ} \mathrm{C}$ for $30 \mathrm{~min}$. The fluorescence of individual cells as analyzed in a FACS as described above. $(\cdot \cdots \cdot),(-\cdot \cdot \cdot)$, and $(-)$ indicate the histogram of unstained IM- 9 cells and IM- 9 cells with bound MV in the presence and absence of unlabeled SP, respectively.

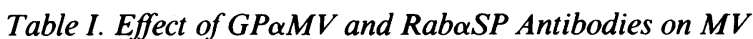
Plaque Formation

\begin{tabular}{clcc}
\hline & & \multicolumn{2}{c}{ Plaque formation } \\
\cline { 3 - 4 } Antibodies & Dilution & Day 4 & Day 6 \\
\hline \multirow{3}{*}{ Control serum } & \multicolumn{3}{c}{ \% of control } \\
& $1: 30$ & $112.0 \pm 13.5$ & $112.0 \pm 13.5$ \\
& $1: 100$ & $99.5 \pm 14.7$ & $99.5 \pm 14.7$ \\
& $1: 300$ & $102.0 \pm 2.9$ & $102.0 \pm 2.9$ \\
GP $\alpha$ MV & $1: 1,000$ & $102.0 \pm 2.9$ & $102.0 \pm 2.9$ \\
& $1: 100$ & $1.0 \pm 0.6^{*}$ & $2.0 \pm 0^{\ddagger}$ \\
& $1: 300$ & $13.3 \pm 0.4^{\ddagger}$ & $17.0 \pm 1.0^{\ddagger}$ \\
Rab $\alpha S P$ & $1: 1,000$ & $26.7 \pm 6.1^{\ddagger}$ & $19.5 \pm 1.5^{\ddagger}$ \\
& $1: 100$ & $5.3 \pm 1.9^{*}$ & $54.3 \pm 5.8^{*}$ \\
& $1: 300$ & $34.8 \pm 5.6^{\ddagger}$ & $108.5 \pm 4.4$ \\
& $1: 1,000$ & $44.0 \pm 9.8^{*}$ & $111.5 \pm 9.5$
\end{tabular}

100-200 plaque-forming units of MV were added into confluent monolayer cultures of Vero cells, and incubated for $1 \mathrm{~h}$ at $37^{\circ} \mathrm{C}$ for virus adsorption in the presence and absence of antibodies. After the viral innoculum was removed, the culture was continued for $3 \mathrm{~d}$ in the presence and absence of the respective antibodies. Plaques were then stained with neutral red and the number of plaques were counted on days 4 and 6 . Each data represent the mean \pm SEM from three to six separate determinations.

*, $P<0.01 ;{ }^{\ddagger}, P<0.001$ compared with control serum.

$\times 100$ of SP and the oligopeptide-pretreated cells were $21.3 \pm 12.7 \%($ mean \pm SEM $)(P<0.05)$, and $42 \pm 2.0 \%(P$ $<0.05)$, respectively. In order to further analyze the specificity of action of SP and the oligopeptide on MV fusion, parallel studies were conducted on the fusion kinetics of VSV. The fusion of VSV with Vero cells occurred shortly after acidification as previously described (15) (Fig. $4 D$ ). However, both SP (Fig. $4 E$ ) and the oligo-peptide (Fig. $4 F$ ) failed to significantly inhibit VSV fusion.

Certain viruses have now been shown to bind to specific

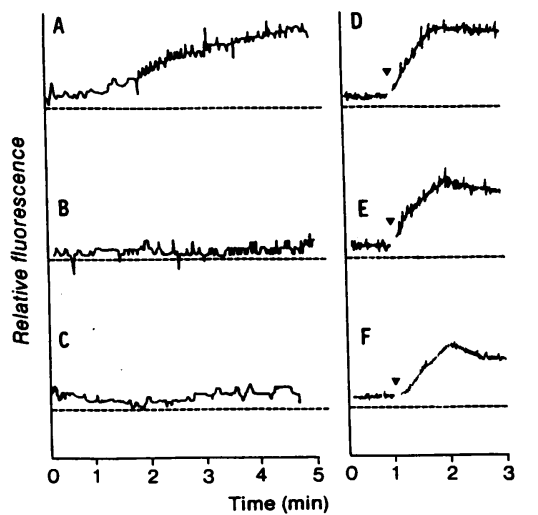

Figure 4. Inhibition of MV fusion by SP. $\mathbf{R}_{18-}$ loaded MV $(A-C)$ or VSV $(D-F)$ were adsorbed to Vero cells for $1 \mathrm{~h}$ at $4^{\circ} \mathrm{C}$. The cells were then resuspended in PBS, and immediately transferred to a cuvette, prewarmed at $37^{\circ} \mathrm{C}$. The change in fluorescence was measured in a fluorimeter at $560 \mathrm{~nm}$ excitation and $585 \mathrm{~nm}$ emission. $(A$ and $D$ ) Control MV and VSV fusion kinetics with untreated Vero cells. $\left(B\right.$ and $E$ ) Vero cells were pretreated with $10^{-7} \mathrm{M} \mathrm{SP}$ overnight, and the fusion assay was performed in the presence of $10^{-8} \mathrm{M} \mathrm{SP}$. ( $C$ and $F$ ) Vero cells were incubated overnight with $10^{-6} \mathrm{M}$ Z-D-Phe-LPhe-Gly and the fusion assay was performed in the presence of $10^{-7}$ $\mathrm{M}$ of the peptide. $\nabla$ indicates the addition of a predetermined amount of $\mathrm{HCl}$ to obtain a final $\mathrm{pH}$ of 5.7. 
cell surface proteins that had been previously identified as receptors for such diverse ligands as neurotransmitters and growth factors (1-5). One mechanism which may explain this evolutionary adaptation is that viral components that are essential for the binding/attachment/fusion process may exhibit structural homologies with naturally occurring ligands and hence "share" cell surface receptors with these endogenous peptides. Our initial RIA demonstrate that antisera directed against the receptor-binding determinants of SP (-Phe-PheGly-Leu-Met- $\mathrm{NH}_{2}$ ) also recognize similar epitopes on the MV (Fig. 1). When MV and SP are specifically cross-linked to ${ }^{35}$ S-biosynthetically labeled cells, Rab $\alpha S P$ immunoprecipitates the same protein from either MV or SP cross-linked preparations (Fig. 2). Parallel studies conducted in a FACS, demonstrated that MV-FITC bound to cells could be specifically displaced by either unlabeled MV or unlabeled SP (Fig. 3). Moreover, reciprocal experiments showed that specifically bound ${ }^{125} \mathrm{I}-\mathrm{SP}$ could also be displaced by MV. Thus the immunoprecipitation and FACS results suggest that both MV and SP are binding to the SPR previously identified by ${ }^{125}$ I-SP cross-linking studies (12). The functional consequences of the above structural interactions were defined by examining the effects of Rab $\alpha$ SP on MV plaque formation (Table I), and SP on MV fusion (Fig. 4). The inhibition of the MV cytopathic effect by Rab $\alpha$ SP, and of MV fusion with Vero cells by SP, indicates that the virus may be using the SPR during a specific phase of the infectious cycle.

To test further the hypothesis that there are specific MVSPR interactions, stable cell lines transfected with SPR cDNA will need to be established, and the various stages of MV infection in SPR positive and negative cells compared. Our results suggest that the SPR may facilitate MV fusion with target cells. These observations may elucidate elements of MV tissue tropism and the pathophysiologic responses observed in distinct tissues to MV infection. Moreover, given the extensive homologies observed in the family of G-protein coupled receptors, it is also possible that MV and other closely associated viruses may recognize a common structural motif on these receptors, and use more than one type of receptor in this family during fusion with specific cells. It should be noted that the contractile responses of guinea pig airways to SP were enhanced by infection with another paramyxovirus (parainfluenza-3) suggesting that a closely related virus may also interact and modulate the activities of the SPR (21).

\section{Acknowledgments}

We would like to thank Dr. J. E. White (UCSF) for providing us with VSV and helpful comments on the fusion assay.

This work was supported by the Howard Hughes Medical Institute and U.S. Public Health Service grant NS-21710.

\section{References}

1. Lentz, T. L., T. G. Burrage, A. L. Smith, J. Crick, and G. H. Tignor. 1982. Is the acetylcholine receptor a rabies receptor? Science (Wash. DC). 215:182-184.

2. Eppstein, D. A., Y. V. Marsh, A. B. Schreiber, S. R. Newman, G. J. Todaro, and J. J. Nestor, Jr. 1985. Epidermal growth factor receptor occupancy inhibits vaccinia virus infection. Nature (Lond.). 318:663-665.

3. Fingeroth, J. D., J. J. Weis, T. F. Tedder, J. L. Strominger, P. A. Biro, and D. T. Fearon. 1984. Epstein-Barr virus receptor of human B lymphocytes is the Cd3 receptor CR2. Proc. Natl. Acad. Sci. USA. 81:4510-4515.

4. McDougal, J. S., A. Mawle, S. P. Cort, J. K. A. Nicholson, G. D. Cross, J. A. Scheppler-Campbell, D. Hicks, and J. Sligh. 1985. Cellular tropism of the human retrovirus HTLV-III/LAV. J. Immunol. 135:3151-3162.

5. Co, M. S., G. N. Gaulton, A. Tominaga, C. J. Homcy, B. N. Fields, and M. I. Greene. 1985. Structural similarities between the mammalian $\alpha$-adrenergic and reovirus type 3 receptors. Proc. Natl. Acad. Sci. USA. 82:5315-5318.

6. Mountcastle, W. E., and P. W. Choppin. 1977. A comparison of the polypeptides of four measles virus strains. Virology. 78:463-474.

7. Scheid, A., and P. W. Choppin. 1977. Two disulfide-linked polypeptide chains constitute the active $\mathrm{F}$ protein of paramyxoviruses. Virology. 80:54-66.

8. Richardson, C. D., A. Scheid, and P. W. Choppin. 1980. Specific inhibition of paramyxovirus replication by oligopeptides with amino acid sequences similar to those at the N-termini of the F1 or HA2 viral polypeptides. Virology. 105:205-222.

9. Richardson, C. D., and P. W. Choppin. 1983. Oligopeptides that specifically inhibit membrane fusion by paramyxoviruses. Virology. 131:518-532.

10. Schroeder, C. 1986. Substance $P$, a neuropeptide, inhibits measles virus replication in cell culture. Acta Virol. (Prague) (Engl. Ed.). 30:432-435.

11. Organist, M. L., J. P. Harvey, J. P. McGillis, and D. G. Payan. 1985. Processing of the human IM- 9 lymphoblasts substance $P$ receptor. Biochem. Biophys. Res. Commun. 151:535-541.

12. Payan, D. G., J. P. McGillis, and M. L. Organist. 1986. Binding characteristics and affinity labeling of protein constituents of the human IM-9 lymphoblast receptor for substance P. J. Biol. Chem. 261:14321-14329.

13. Laemmli, U. K. 1970. Cleavage of structural proteins during the assembly of the head of bacteriophage T4. Nature (Lond.). 227:680-685.

14. McGrath, M., O. Witte, T. Pincus, and I. L. Weissman. 1978. Retrovirus purification. J. Virol. 25:923-927.

15. Blumenthal, R., A. Bali-Puri, A. Walter, D. Covell, and O. Eidelman. 1987. pH-dependent fusion of vesicular stomatitis virus with Vero cells. Measurement by dequenching of octadecyl phodamine fluorescence. J. Biol. Chem. 262:13614-13619.

16. McGillis, J. P., M. L. Organist, and D. G. Payan. 1987. Immunoaffinity purification of membrane protein constituents of the IM-9 lymphoblast receptor for substance P. Anal. Biochem. 164:502513.

17. Krah, D. L., and P. W. Choppin. 1988. Mice immunized with measles virus develop antibodies to a cell surface receptor for binding virus. J. Virol. 62:1565-1572.

18. Varsanyi, T. M., G. Utter, and E. Norrby. 1984. Purification, morphology and antigenic characterization of measles virus envelope components. J. Gen. Virol. 65:355-366.

19. Norrby, E. 1985. Measles. In Virology. B. N. Fields et al., editors. Raven Press, Ltd., New York. 1305-1321.

20. Lampert, P. W., B. S. Joseph, and M. B. A. Oldstone. 1976. Morphological changes of cells infected with measles or related viruses. Prog. Neuropathol. 3:51-69.

21. Saban, R., E. C. Dick, R. I. Fishleder, and C. K. Buckner. 1987. Enhancement by parainfluenza 3 infection of contractile responses to substance $\mathrm{P}$ and capsaicin in airway smooth muscle from the guinea pig. Am. Rev. Respir. Dis. 136:586-591. 